\title{
Altas habilidades ou superdotação em Liderança: uma proposta de identificação e atendimento
}

\author{
High abilities or giftedness in Leadership: a proposal of identification and service \\ Altas capacidades o sobredotación en Liderazgo: una propuesta de identificación y atendimiento
}

Recebido: 14/12/2021 | Revisado: 21/12/2021 | Aceito: 24/12/2021 | Publicado: 04/01/2022

\author{
Clairen Angélica Santiago de Oliveira \\ ORCID: https://orcid.org/0000-0002-8686-3960 \\ Prefeitura Municipal de Indaiatuba, Brasil \\ Grupo de Pesquisa para o Desenvolvimento do Potencial Humano, Brasil \\ E-mail: clairenangelicasantiago@gmail.com \\ Rosemeire de Araújo Rangni \\ ORCID: https://orcid.org/0000-0002-8752-9745 \\ Universidade Federal de São Carlos, Brasil \\ Grupo de Pesquisa para o Desenvolvimento do Potencial Humano, Brasil \\ E-mail: rose.rangni@uol.com.br
}

\begin{abstract}
Resumo
Liderança é uma das áreas de capacidade viabilizada nas altas habilidades ou superdotação (AHSD). Assim, este artigo objetiva apresentar a identificação e uma proposta de intervenção para estudantes com características de Liderança do Ensino Fundamental I de uma escola pública. A pesquisa valeu-se de desenho descritivo e de pesquisa-ação. Participaram cento e noventa (190) estudantes e quinze professores. Foram aplicados questionários para indicação de AHSD e checklista. Os resultados apresentaram a indicação de sete estudantes, sendo quatro meninos e três meninas. Também, realizaram-se enriquecimentos I e II aos discentes indicados na sala de recurso multifuncional, em contraturno. Eles puderam vivenciar atividades diferenciadas do cotidiano escolar, as quais foram avaliadas positivamente por eles e pela professora-pesquisadora responsável pelos enriquecimentos. Entende-se, que o estudo desenvolvido contribui para discussões na área de AHSD em Liderança, especialmente em crianças pequenas.
\end{abstract}

Palavras-chave: Altas habilidades; Liderança; Superdotação.

\begin{abstract}
Leadership is one of de field of High Abilities or Giftedness (AHSD). Thus, this article aims to present the identification and a proposal of intervention to the students with Leadership characteristics in the Elementary School of a public network. The research was descriptive and action-research. One hundred and ninety students and fifteen teachers were participants. AHSD nomination questionnaires and checklist were applied. The results presented the indication of seven students, four boys and three girls. Also, the enrichments I and II were realized to the indicated students in the resource room, in counter shift. The students were able to experience different activities in addition the school routine, which were positively evaluated by them and by the teacher-researcher responsible for the enrichments. It is understood that the study developed contributes to the discussions of AHSD in Leadership, especially to the young children.
\end{abstract}

Keywords: High abilities; Leadership; Giftedness.

\section{Resumen}

Liderazgo es una de las áreas de capacidad de las altas capacidades (AHSD). Así, este artículo tiene el objetivo de presentar la identificación y una propuesta de intervención para estudiantes con características de Liderazgo en la Primaria I de una escuela pública. La investigación fue descriptiva y de investigación-acción. Participaron ciento noventa alumnos y quince profesores. Se emplearon cuestionarios para la indicación del AHSD y una lista de comprobación. Los resultados mostraron la indicación de siete estudiantes, cuatro chicos y tres chicas. Tras la indicación, fueron realizados los enriquecimientos I y II a los estudiantes indicados en la sala de recursos, fuera de turno. Eles pudieron experimentar diferentes actividades fuera de la rutina escolar, que fueron evaluadas positivamente por ellos y por el profesor-investigador responsable por los enriquecimientos. Se entiende que el estudio desarrollado contribuye para las discusiones para AHSD en Liderazgo, especialmente para los niños pequeños.

Palabras clave: Altas capacidades; Liderazgo; Superdotación. 


\section{Introdução}

A Política Nacional de Educação Especial na Perspectiva da Educação Inclusiva, de 2008, define os estudantes com Altas Habilidades ou Superdotação (AHSD) sendo aqueles com desenvolvimento ou potencial elevados em qualquer das áreas: Intelectual, Acadêmica, Liderança, Artística, Criatividade e Psicomotricidade, menciona-se, também, que esses estudantes pertencem ao público da Educação Especial com direitos ao atendimento educacional especializado (AEE). Renzulli (2021) afirma que $10 \%$ a $15 \%$ da população mundial têm comportamento de AHSD.

Como pode ser notado, entre as áreas está a Liderança. Sobre ela, Gardner (2013) diz que a nossa herança primata é imprescindível para a análise da Liderança, pois, diferentemente de outros primatas nos organizamos em hierarquias, reconhecemos os membros individuais das espécies e competimos uns com os outros por posições e assumimos relações específicas de dominância ou de submissão com os coespécimes.

Entre as Inteligências Múltiplas, teorizadas por esse autor (1994), a inteligência interpessoal, a qual a Liderança está inserida, externaliza para outros indivíduos a capacidade de observação e distinção de pessoas, humores, temperamentos, intenções e motivações. Ramos-Ford e Gardner (1991) citados por Sisk (2000) assinalam as características intelectuais, interpessoais: senso de justiça, inteligência precoce como a capacidade de compreender os outros indivíduos e preocupação moral por se caracterizarem de forma produtiva nas ações e motivações do líder, pois, liderar outras pessoas tem um peso significativo a ponto de enxergar valores e potenciais de outras pessoas em si mesmo, afirmam Covey et al. (2017).

Quanto ao fator emocional, Goleman (2015) questiona se para a Liderança é mais importante o Quociente de Inteligência (Q.I) ou o Quociente Emocional (Q.E). O citado autor responde que não há dúvida de que o Q.I é a melhor forma de encaminhar as pessoas para as carreiras mais adequadas, já que é preciso um desvio de padrão para lidar com a complexidade cognitiva de determinadas profissões. Porém, quando essas pessoas gabaritadas intelectualmente exercem funções de Liderança pode haver um "efeito piso", ou seja, a provisão do sucesso decai gradualmente, porque o que contará para a proficiência será a produtividade, a coletividade, o destaque entre os membros da equipe e, por essa ótica, o Q.E passa a ter mais importância, assevera Goleman.

Nessa perspectiva, a Liderança como manifestação de AHSD é reconhecida, porém as escolas não a têm potencializado, em detrimento de outras áreas. Mas, como identificar os estudantes com características de AHSD em Liderança? Sobre essa perspectiva, o cientista norte-americano Joseph Renzulli desenvolveu o School Enrichment Model (SEM) no qual está inserida a Teoria dos Três Anéis. Ele assegura que o comportamento superdotado (termo empreendido por ele) se dá por meio da interação entre três conjuntos (anéis) - habilidade acima da média, envolvimento com a tarefa e criatividade (Renzulli, 2014) e, destaca que a interação é imprescindível entre eles, no entanto, não precisam estar na mesma proporção (Renzulli e Reis, 1997).

O objetivo do SEM é introduzir no currículo escolar regular oportunidades de atendimento e recursos como subsídio aos professores para que a suplementação se efetive por meio de aprendizagens e experiências a toda a escola (Renzulli, 2014, 2018; Koga, Rangni e Rossi, 2021). O Modelo Triádico de Enriquecimento, criado em 1970, faz parte do SEM e consiste em Enriquecimento do Tipo I, Tipo II e Tipo III, os quais oferecem atividades a partir dos interesses dos estudantes até tornarem-se especialistas ao desenvolverem produtos criativos para compartilhar com públicos interessados (Burns, 2014; Renzulli, 2014). O modelo trabalha as inúmeras habilidades e potenciais dos estudantes, progressivamente, e aumenta a quantidade de adultos criativo-produtivos (Reis \& Renzulli, 2009). Esse modelo oferece possibilidades de identificar potenciais a serem desenvolvidos.

Sobre Liderança, Pfeiffer e Wechsler (2013) afirmam que se sabe muito sobre líderes, especialmente quando relacionados com organizações, governos e militares, entretanto, educadores e psicólogos sabem pouco como ela se desenvolve na juventude e sua relação com a inteligência.

A partir desses breves apontamentos, este artigo tem como objetivo apresentar a identificação e uma proposta de 
intervenção para estudantes com características de Liderança do Ensino Fundamental I de uma escola pública; fruto de pesquisa de Mestrado desenvolvida em 2019.

\section{Metodologia}

A pesquisa se desenha em descritiva e pesquisa-ação, que segundo Gil $(2002,2008)$ a descrição das características de determinada população ou fenômeno e estabelecimento de relações entre variáveis. A pesquisa-ação consiste em "mudar uma situação particular, levando em consideração a totalidade concreta tal como é vivida" (Dionne, 2007, p. 23).

O local da pesquisa foi uma escola pública municipal de período integral do interior do Estado de São Paulo, com aproximadamente 260 estudantes matriculados no Ensino Fundamental I e é uma escola de período integral.

O estudo percorreu duas etapas - 1. Identificação e 2. Enriquecimento. Os participantes dessas etapas estão representados na Tabela 1.

Tabela 1 - Estudantes participantes da pesquisa.

\begin{tabular}{c|c|c}
\hline Participantes/serie & Idade & Gênero \\
\hline $\mathrm{A} 1 / 1^{\circ} \mathrm{A}$ & 7 & Feminino \\
\hline $\mathrm{A} 2 / 1^{\circ} \mathrm{A}$ & 7 & Masculino \\
\hline $\mathrm{A} 3 / 2^{\circ} \mathrm{A}$ & 8 & Feminino \\
\hline $\mathrm{A} 4 / 2^{\circ} \mathrm{A}$ & 8 & Masculino \\
\hline $\mathrm{A} 5 / 2^{\circ} \mathrm{B}$ & 8 & Feminino \\
\hline $\mathrm{A} 6 / 2^{\circ} \mathrm{B}$ & 8 & Feminino \\
\hline $\mathrm{A} 7 / 4^{\circ} \mathrm{A}$ & 9 & Feminino \\
\hline $\mathrm{A} 8 / 4^{\circ} \mathrm{A}$ & 9 & Masculino \\
\hline $\mathrm{A} 9 / 5^{\circ} \mathrm{A}$ & 10 & Masculino \\
\hline $\mathrm{A} 10 / 5^{\circ} \mathrm{A}$ & 10 & Masculino \\
\hline $\mathrm{A} 11 / 5^{\circ} \mathrm{B}$ & 10 & Masculino \\
\hline $\mathrm{A} 12 / 5^{\circ} \mathrm{B}$ & 10 & Masculino
\end{tabular}

Fonte: Elaboração própria.

Participaram doze (12) estudantes do $1^{\circ}$ ao $5^{\circ}$ Ano, meninas e meninos, com idade entre sete (7) e dez (10) anos.

Quantos aos instrumentos empregados:

(Etapa 1) a) Questionário: construído com perguntas livres e fechadas aos professores e gestores, divididas em categorias: caracterização do participante, idade, sexo, tempo de formação e atuação, conhecimento sobre a temática de altas habilidades ou superdotação, concepção acerca da liderança. Esse instrumento passou por juízes para adequação semântica; b) Lista de verificação de indicadores de AHSD (LIVIAHSD), de Pérez e Freitas (2016). Trata-se de um instrumento de triagem respondido pelo(a) professor(a) regente ou pelos professores e cada disciplina, no Ensino Fundamental, Médio e Superior, exceto Educação Artística e Educação Física, que possuem instrumentos específicos; c) Questionário para identificação de indicadores de AHSD, QIIAHSD-PR (Questionário para Identificação de Indicadores de Altas Habilidades/Superdotação - Professor), das mesmas autoras. São cinco blocos de indicadores, tais quais: características gerais, com dezesseis indicadores que discorrem sobre habilidades escolares; habilidade acima da média, com doze indicadores; a criatividade, com quinze indicadores, o comprometimento com a tarefa, com treze indicadores e, ainda, um bloco sobre liderança, podendo ser negativa ou positiva e se manifesta pelos seguintes indicadores: elevada persuasão; capacidade de argumentação e convencimento; autossuficiência; 
tendência a organizar grupo; e capacidade de cooperação; d) Checklista de Nomeação de Liderança (CNL), o qual compõe-se de vinte e três (24) itens. São eles: 1- Autoconceito positivo; 2- Mente aberta; 3- Capacidade verbal; 4- Atitude questionadora; 5- Reflexivo (a), 6- Sensível, empático (a); 7- Tolerante às ambiguidades; 8- Sensibilidade às injustiças; 9- Honestidade; 10Independente; 11- Persistente; 12- Sociável; 13- Arrisca-se; 14- Capacidade de tomar decisões; 15- Seriedade; 16- Crítico (a); 17- Entusiasmado (a); 18- Flexibilidade de pensamento e ação; 19- Necessidade de realização; 20- Nível alto de energia; 21Grande número de interesses; 22- Curiosidade; 23- Dominante; 24- Responsabilidade, respaldados em Vidergor e Sisk (2013).

(Etapa 2) a) Protocolo de Investigação dos Interesses dos Alunos com Indicadores de Liderança (PIIAIL), a partir de dez tópicos preferidos e escolhidos no inventário pelo interesse do aluno; b) Inventário: "Eu Gostaria de Saber Mais Sobre..." composto por 290 tópicos subdivididos nas áreas de Estudos Sociais, Comunicação e Expressão, Ciências, Arte, Recreação/Hobbies, Profissões/Vocações, Matemática e Habilidades de Pensamento/Pesquisa/Estudo; c) Projeto de Enriquecimento em Liderança (PEL), ambos baseados em Burns (2014),

A coleta de dados seguiu os seguintes passos:

(Etapa1) I) Contato com a Secretaria de Educação do Munícipio pesquisado;

II) Contato com a escola para exposição do projeto e autorização pelos participantes;

III) Primeira capacitação aos professores e aos gestores da escola em horário de trabalho pedagógico coletivo (HTPC) sobre a temática AHSD com duração de quatro horas;

IV) Dos dezoito professores, que estiveram no HTPC, quinze participaram, respondendo questões como: identidade, formação inicial, continuada, tempo de atuação como docente, tempo de atuação como docente na escola pesquisada, a disciplina, projeto e ano que atuam; o que entendem por AHSD; conhecimento do público alvo da educação especial; processo de identificação dos estudantes com AHSD, dentre outras;

V) Aplicação dos instrumentos: LIVIAHSD em todos os alunos da sala e QIIAHSD-PR aos professores dos doze alunos indicados. Participaram os professores de sala comum e o dos projetos desenvolvidos em contraturno.

VI) Construção, adaptação, correção semântica (por juízes) e aplicação do instrumento Checklista de Nomeação de Liderança (CNL), a partir dos indicadores de Liderança;

VII) Aplicação do CNL a dois professores para adequação semântica.

(Etapa 2) I) Contato e informação sobre os procedimentos aos sete alunos indicados com AHSD em Liderança;

II) Contato com os pais ou responsáveis dos estudantes indicados para a leitura do Termo de Consentimento Livre e Esclarecido, para autorizarem a participação dos filhos e assinatura do Termo de Assentimento Livre e Esclarecido;e

III) Encaminhamentos para a Atividade do Tipo I, Projeto de Enriquecimento em Liderança (PEL) e a leitura do inventário: "Eu Gostaria Saber de mais Sobre..." e escolha dos tópicos de interesse de cada estudante.

Quanto aos procedimentos de análise de dados foram:

(Etapa 1) I) Organização de uma pasta catálogo com todos os questionários preenchidos para o arquivamento de forma digital e a leitura das repostas do questionário dos professores para análise por semelhança e síntese em quadros e tabelas;

II) Análise do LIVIAHSD, de acordo com o manual de Pérez e Freitas (2016) e sistematizados em quadros, tabelas e gráficos;

III) Análise do questionário QIIAHSD-PR;

IV) Os instrumentos LIVIAHSD e QIIAHSD-PR foram analisados de acordo com o manual orientador de Pérez e Freitas (2016). Para apresentar os resultados de forma quantitativa, usou-se como estratégia atribuir valores (1 a 5 pontos) nas frequências dos comportamentos indicados no instrumento na seguinte ordem: Nunca (1 ponto); Raramente: (2 pontos); Às vezes: (3 pontos); Frequentemente: (4 pontos); Sempre: (5 pontos). Sendo assim, o total máximo de pontos pode alcançar 25 , uma vez que somente Frequentemente (4 pontos) e Sempre (5 pontos) são contabilizados para apontar características de 
Liderança. No tocante ao LIVIAHSD, a interpretação levou em conta o percentual de indicações de cada um dos alunos com pelo menos em $51 \%$ das questões de 1 a 24, ou seja, ao menos treze (13) vezes, além da (as) citações na questão 25 . Vale lembrar, todavia, que o instrumento não atribui valores aos itens, assim, pensou-se como critério para a indicação que o participante atingisse no mínimo sessenta por cento $(60 \%)$ na indicação "FREQUENTEMENTE" e "SEMPRE"; e

V) Análise das respostas obtidas no instrumento CNL, que antecipadamente foi aplicado a dois professores não participantes para verificação semântica e, houve formulação da frequência para as respostas, quais sejam: nunca (0 ponto), às vezes ( 1 ponto), frequentemente ( 2 pontos) e sempre ( 3 pontos), sendo que a indicação deve atingir no mínimo sessenta por cento (60\%) na mensuração "frequentemente" e "sempre". Na adaptação do CNL, pensou-se em cem por cento (100\%) de indicativos de SEMPRE, com a pontuação três (3), multiplicados por vinte e quatro (24) itens, resultam um total máximo de setenta e dois (72) pontos, sendo FREQUENTEMENTE, pontuação dois (2); ÀS VEZES, pontuação um (1); NUNCA, pontuação zero (0). As respostas foram arquivadas em pasta catálogo e sistematiza-las em quadros e tabelas.

(Etapa 2) I) Após a realização da Atividade do Tipo I, em consenso, os estudantes selecionaram um único tópico: "Valores/Educação Moral" e, deu-se início à Atividade do Tipo II com a exploração da temática de interesse do grupo. Eles pesquisaram e elaboraram um projeto de valores morais e de inteligência emocional. Essa atividade ocorreu na sala de recursos sob a supervisão da professora/pesquisadora. As etapas foram observadas e registradas.

O estudo desenvolvido cumpriu os procedimentos éticos, de acordo com os termos da Resolução 466/2012 do Conselho Nacional de Saúde, por meio do CAEE 92746818.3.0000.5504

\section{Resultados}

\section{Etapa 1- Identificação}

Foi construído um questionário com perguntas livres e fechadas aos professores, divididas em categorias, tais quais: caracterização do participante, idade, sexo, tempo de formação e atuação, conhecimento sobre a temática de AHSD e sobre Liderança. Neste artigo serão apresentadas análise de dados relacionadas aos professores respondentes.

Dentre os professores que aceitaram participar (15) apenas um era do gênero masculino. Em relação à formação acadêmica, todos são graduados em licenciatura, dez com pós-graduação (especialização). Entre eles, três eram ingressantes recentes na escola e a maioria especialista. Ao analisar as respostas do questionário, houve a percepção de fragilidade para a equidade, pois ainda o público alvo da Educação Especial não é compreendido e identificado pelos professores, como também, a conciliação da teoria com a prática é tarefa desafiadora aos docentes.

Foram seis turmas de estudantes observadas pelos professores do ensino regular (matutino) e turmas de projetos (vespertino), sendo que somente os $3^{\circ}$ Anos A e B não houveram indicados para esta primeira triagem, pois, o professor da tarde $\left(3^{\circ} \mathrm{A}\right)$ elencou zero $(0)$ e o professor vespertino $\left(3^{\circ} \mathrm{B}\right)$ não preencheu a lista de verificação, portanto, por isso houve uma diminuição no número total de alunos, de 239, inicialmente, para 190. Desses, doze (12) foram indicados no QIIAHSD-PR (6,3\%), como expõe a Tabela 2. 
Tabela 2 - Pontuação obtida pelos estudantes no QIIAHSD-PR.

\begin{tabular}{|c|c|c|c|c|c|c|c|c|c|c|c|c|}
\hline \multirow[b]{2}{*}{ Itens } & \multicolumn{12}{|c|}{ Resultado - QIIAHSD-PR } \\
\hline & A1 & A2 & A3 & A4 & A5 & A6 & A7 & A8 & A9 & A10 & A11 & A12 \\
\hline É autossuficiente? & 4 & 5 & 4 & 2 & 4 & 4 & 2 & 5 & 3 & 4 & 4 & 4 \\
\hline $\begin{array}{l}\text { É escolhido(a) pelos seus colegas e amigos para } \\
\text { funções de líder (líder de turma, coordenador(a)? }\end{array}$ & 4 & 3 & 2 & 3 & 3 & 4 & 3 & 5 & 3 & 4 & 4 & 5 \\
\hline É cooperativo(a) com os demais? & 4 & 4 & 3 & 3 & 4 & 3 & 3 & 5 & 4 & 4 & 4 & 5 \\
\hline Tende a organizar o grupo? & 4 & 4 & 3 & 3 & 5 & 3 & 3 & 5 & 3 & 4 & 4 & 4 \\
\hline $\begin{array}{l}\text { Sabe se expressar bem e convence os outros com } \\
\text { os seus argumentos? }\end{array}$ & 4 & 4 & 3 & 5 & 4 & 3 & 2 & 5 & 4 & 4 & 4 & 4 \\
\hline Total de Pontos & 20 & 20 & 15 & 16 & 20 & 17 & 13 & 25 & 17 & 20 & 20 & 22 \\
\hline Percentual & $80 \%$ & $80 \%$ & $60 \%$ & $64 \%$ & $80 \%$ & $68 \%$ & $52 \%$ & $100 \%$ & $68 \%$ & $80 \%$ & $80 \%$ & $88 \%$ \\
\hline
\end{tabular}

Fonte: Elaboração própria.

Entre os doze alunos indicados, apenas um não atingiu o percentual mínimo de $60 \%$ estabelecido como critério. Assinala-se, que A8 atingiu $100 \%$ de indicação.

O instrumento empregado contempla caratecterísticas abrangentes, no entanto, mais relevantes para esta pesquisa são as características da Liderança, quais sejam: Elevada persuasão; Capacidade de argumentação e convencimento; Autossuficiência; Tendência a organizar o grupo; e Capacidade de cooperação.

No sentido de complementar a indicação anteriores, apresentam-se os resultados da Checklista de Nomeação de Liderança (CNL). Nesse instrumento, Onze alunos foram indicados e os resultados encontram-se na Tabela 3:

Tabela 3 - Pontuações dos estudantes no CNL.

\begin{tabular}{l|l|l}
\hline Estudantes & Pontuação & \% \\
\hline A1 & 37 & $55 \%$ \\
\hline A2 & 36 & $53 \%$ \\
\hline A3 & 35 & $51 \%$ \\
\hline A4 & 44 & $65 \%$ \\
\hline A5 & 50 & $73 \%$ \\
\hline A6 & 35 & $51 \%$ \\
\hline A8 & 66 & $96 \%$ \\
\hline A9 & 46 & $67 \%$ \\
\hline A10 & 44 & $65 \%$ \\
\hline A11 & 46 & $67 \%$ \\
\hline A12 & 52 & $76 \%$ \\
\hline
\end{tabular}

Fonte: Elaboração própria.

Os estudantes A1, A2, A3 e A6 não atingiram a média estabelecida nesse instrumento complementar, desta forma, foram selecionados com indicadores de Liderança sete alunos (quatro meninos e três meninas), quais sejam: A4, A5, A7, A, 8, A9, A10, A11 e A12, sendo que A8 atingiu a melhor pontuação.

Após os instrumentos analisados, em síntese, foram esses os resultados da Etapa 1: 
Total de matrículas: (239); Estudantes participantes (190); Estudantes indicados (12); Estudantes indicados no QIIAHSDPR (11); Indicações no CNL (07); Indicação Final (07).

\section{Etapa 2 - Enriquecimento}

O PEL foi executado em dois momentos: Enriquecimento do Tipo I e do Tipo II.

No Enriquecimento do Tipo I os estudantes indicados com características de Liderança exploraram o inventário de interesse, o qual contém uma lista com duzentos e noventa tópicos (BURNS, 2014). Após os estudantes os lerem, eles escolheram dez temas que gostariam de explorar como atividades para o Tipo I. Essas escolhas discorreram sobre Estudos Sociais; Comunicação e Expressão; Ciências; Artes; Recreação/Hobbies; Profissões/Vocações; Matemática e Habilidades de: Pensamento/Pesquisa/Estudo. Os estudantes analisaram e discutiram sobre as características de Liderança para que pudessem se apropriar do tema a ser selecionado por eles. Duas aulas com duração de uma hora e meia ocorreram com espaço temporal de quinze dias. Os dez tópicos são: Álcool e drogas; História em Quadrinhos; Astronomia; Dinossauros; Arte Popular; Esportes; Líderes; Saúde Mental; Criatividade e Valores/Educação Moral

Após essa seleção dos dez temas, foi escolhido um único, sugerido por um dos participantes que fizessem uma votação entre eles. Todos deram uma nota de zero a dez para cada tema, chegando ao resultado, conforme mostra o Gráfico 1.

Gráfico 1 - Temas escolhidos.

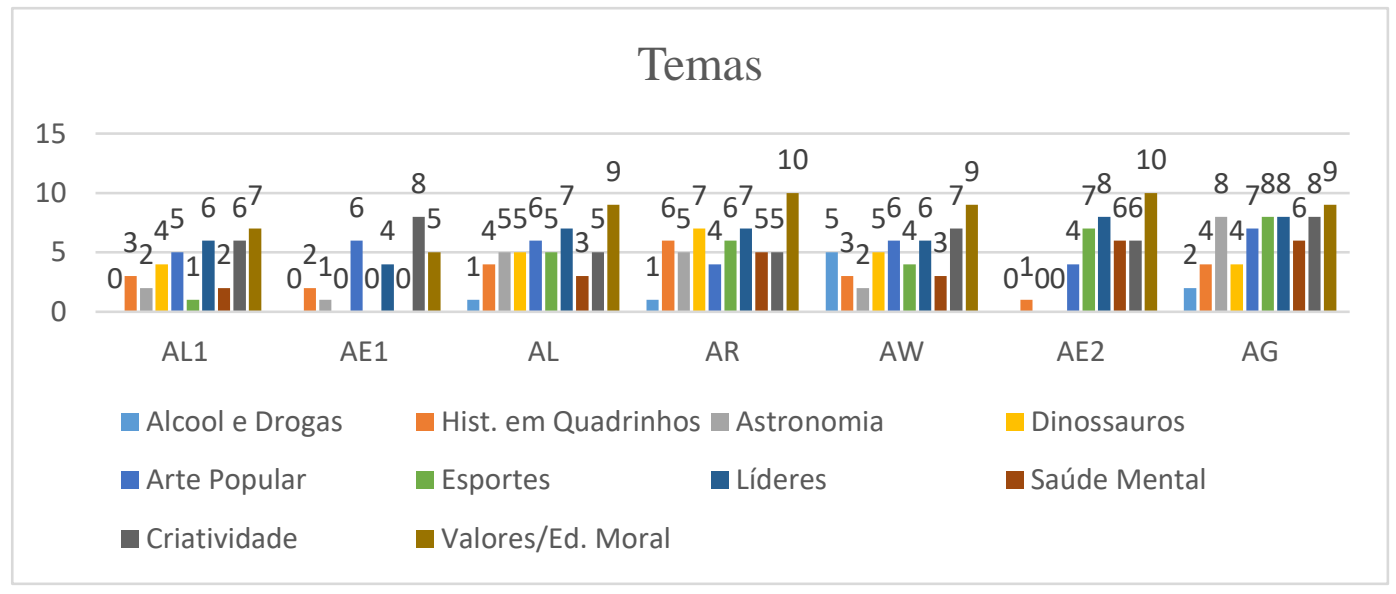

Fonte: Elaboração própria.

Diante desses resultados, percebe-se que "Valores/Educação Moral” foi de maior interesse entre os estudantes. Para tanto, ocorreram sete seções (aulas) e nas quatro últimas os estudantes foram convidados a participar de duas aulas no $4^{\circ}$ Ano $\mathrm{A}$ em assembleia de classe, em que a professora regular juntamente com a professora/pesquisadora desenvolveram um projeto de ética e moralidade infantil a partir do comportamento opositor apresentado por alguns discentes daquela turma. A aula foi realizada com dinâmicas que instigavam o campo emocional, como reflexões por meio de músicas, roda do diálogo, qualificar os amigos e a si próprio, empatia e inclusão. Naquela turma havia um discente com transtorno do espectro autista e o grupo dos estudantes participantes soube que a sociabilidade e afetividade do colega haviam sido elevadas em cinquenta por cento (50\%) com essas intervenções, segundo as professoras.

Nas duas seções subsequentes, os participantes realizaram estudos na sala de recursos com a temática: "Valores e Educação Moral", com mediação da professora/pesquisadora. A escolha do tema "Valores/Educação Moral" foi justificada pelos 
participantes por terem o projeto pedagógico "Ética e Moralidade Infantil" na matriz curricular. Nessas aulas foram oferecidos vídeos de palestras, leitura e discussão de artigos em revistas e blogs de projetos desenvolvidos na cidade, estado e país.

As atividades dos encontros para o Enriquecimento do Tipo I foram: I) Apresentação Introdutória para os Alunos Indicados com AH/SD em Liderança; II) Modelo Triádico de Enriquecimento; III) Estas são Algumas das Nossas Coisas Favoritas; IV) Nossos Dez Tópicos Preferidos para Atividades do Tipo I; V, VI) Assembleia de Classe; e VII) Tecendo uma Teia de Tópicos. Esse Enriquecimento foi finalizado com uma análise crítica e uma produção textual coletiva sobre o tema, sendo que a justificava de tal escolha foi com base nos referenciais estudados nas aulas do $4^{\circ}$ Ano A, cujo um dos trechos encontra-se a seguir.

Antes de participar deste grupo tínhamos como certo que os líderes da nossa sala eram aqueles escolhidos para representar a sala nos conselhos de classe a cada bimestre. Alguns de nós aqui até somos esses líderes representantes, mas outros colegas que também estão aqui não são e estudando sobre a liderança, compreendemos sobre os variados tipos de líderes, então, agradecemos a oportunidade de podermos estar aqui, somos privilegiados, portanto queremos dar o nosso melhor neste processo de enriquecimento, principalmente colaborando com as nossas salas, amigos de toda a escola, professores, funcionários, gestores e nossos familiares (Produção coletiva).

Após o término, encaminhou-se para o Enriquecimento do Tipo II, que consiste em atividades de treinamento. São atividades que ensinam alguma habilidade que possibilita ser um melhor aprendiz, pensador ou investigador, sobretudo porque os estudantes podem desenvolver a criatividade, a capacidade de resolver problemas, tomada de decisões ou aprender outras habilidades, assevera Burns (2014).

Os estudantes julgaram aprofundar a temática no AEE para criarem propostas no sentido de liderarem projetos aos colegas da sala, professores, gestores e funcionários. Assim, por solicitação deles, incluiu-se outro tema sobre valores e ética - o Quociente Emocional (Q.E). Os referenciais se respaldaram em Goleman (2011, 2015).

Os recursos explorados para essa fase foram: vídeos, animações, documentários, artigos e livros sobre inteligência emocional explorados aproximadamente seis aulas, aproximadamente. Para isso, foram propostas as atividades/temas:

a) Roda da Conversa: O que Você Entende por Q.E?; b) Vídeo: Q.E (resenha animada); c) Audiobook: resumo do livro "Q.E” (Goleman, 2011); d) Estudo do texto: “A Formação de um Líder" (Daniel Goleman, 2015); e) Estudo do Texto: "Como Alcançar os Objetivos da Escola” (Stephen R. Covey, Sean Covey, Muriel Summers, David K. Hatch, 2017) e f) Proposta para Atividade do Tipo III.

Na primeira seção foi explorado o entendimento dos estudantes sobre Q.E. Uma das respostas dos participantes foi a seguinte:

O Q.E me ajudou a encarar meus medos, minhas ansiedades, estou levando para casa e compartilhando as atividades e dinâmicas com a minha família. Espero que a escola nunca mais deixe de trabalhar com a inteligência emocional, ela nos ajuda inclusive na inteligência intelectual, quando estou mais calmo, tranquilo, percebo que desenvolvo melhor as atividades escolares (A7).

Para além, os estudantes construíram um cartaz em que relacionavam conceitos de Q.E e Liderança, exposto na sala de recursos, como também, foram trabalhados os perfis de Liderança (cultura altamente ineficaz versus cultura altamente eficaz) por meio dos conceitos propostos por Covey et al. (2017). Em sequência, um dos perfis construídos pelos estudantes:

Trabalham isoladas. As pessoas trabalham sozinhas ou em pequenos grupos. Acham que suas ideias sempre são as melhores. Evitam pessoas que pensam de modo diferente. Criam sinergia. As pessoas buscam as ideias dos outros e valorizam a diversidade. São humildes. Possuem alto nível de criatividade e trabalham em grupo. Sentem-se livres para pensar de modo inovador (Participantes). 
Em relação à experiência dos estudantes sobre o PEL desenvolvido, A2 pontua que: "Eu sempre pensei que pudesse ser líder, mesmo nunca sendo escolhido para representar a minha sala. Aprender sobre liderança e QE me fez enxergar o quanto precisamos evoluir como pessoas".

\section{Discussão}

Renzulli (2014) enfatiza a importância da identificação de todos os estudantes para que possam usufruir dos serviços específicos, e, orienta que a teoria é contribuinte para as estratégias práticas para a identificação de alunos com AHSD. Entretanto, ele ressalva que há um enorme desafio neste processo escolar, pois os instrumentos são flexíveis, muitas vezes conflitam com as normativas e regulamentos tradicionais do sistema de ensino; seja ele qual for.

Esse mesmo autor ao debater sobre o capital social discorre que pesquisadores concordam que a "Liderança é uma condição necessária para a criação do capital social” (p. 250). E, acrescenta, que embora inúmeros estudos e comentários sobre Liderança tenham sido discutidos na literatura da educação de AHSD ninguém ainda examinou a relação entre as características dos líderes e suas motivações para usar seus talentos para um público bem maior. Nesse sentido, Gardner (2013) alude que pensar em lideres é visualizar eminentes políticos ou militares, por exemplo.

Ele exemplifica o comportamento de Liderança em polos diferentes, sendo importante analisar os influenciadores que, de alguma forma, contribuíram com a sociedade, como Churchill e Einstein, dois extremos de perfis que denotam a capacidade de influenciar outras pessoas. O primeiro exerceu sua habilidade de maneira direta, por meio das histórias que transmitiu a vários públicos e o segundo exerceu sua influência de maneira indireta, pelas ideias que desenvolveu, constituindo suas teorias. O referido autor acrescenta que alguns dos líderes em potenciais estudos se caracterizavam pela popularidade, sobretudo porque eram requisitados pelos colegas desde a infância, outros já se caracterizavam pela solidão, pelo isolamento, insociabilidade, quando não, criminosos. Gardner exemplifica a respeito da diversidade comportamental de Churchill, pois, ele passava boa parte do tempo sozinho, já Mussolini foi expulso duas vezes da escola por agredir os colegas, Freud era precocemente fascinado por questões de poder e estratégia e Einstein não se interessava pelo mundo dos outros cidadãos.

A respeito da diversidade entre os indivíduos, Reis e Renzulli (2009) pontuam que devemos celebrar as diferenças, apresentar ao mundo os talentosos, propiciar ambientes, encorajamento financeiro e emocional para que possam criar. Eles questionam: "Imagine como seria este mundo sem Beethoven, Pasteur...? Imagine o que aconteceria se alguns dos mais talentosos criadores de nossa civilização fossem forçados a se conformar e não recebessem nenhum apoio?” (pp. 196-197). Por isso, é relevante promover a criatividade produtiva, tanto em crianças como em adultos.

Na perspectiva educacional, Covey et al. $(2017$, p.12) salienta a responsabilidade de liderança dos estudantes "a maioria das escolas dá responsabilidade de liderança aos alunos, mas limita o processo a uns poucos escolhidos que se mostram merecedores ou foram eleitos pelos colegas". Assim, seria interessante a percepção de educadores junto aos seus discentes em desenvolver o poder pessoal da criatividade, percepção, sensibilidade, visão, versatilidade, foco, paciência e habilidades de conflitos (Sisk, 2000).

No presente estudo, o resultado obtido atingiu a estimativa de 3 a $5 \%$ de pessoas com AHSD, de acordo com o Relatório Marland, de 1972, a partir da aplicação dos protocolos de Pérez e Freitas (2016) e do CNL. Farias e Wechsler (2014) apontam que o percentual pode chegar a 20\%, 1\% para as características de genialidade e os outros $19 \%$ para características de habilidades diversas, consideradas pelo desempenho acima da média, enquanto Renzulli (2014) afirma que pode chegar a 15\%.

Sobre o resultado obtido de quatro meninos e três meninas entre os indicados, Goleman (2015) afirma que as pessoas costumam perguntar se essas diferenças de gênero influenciam as habilidades de inteligência social importantes à Liderança e 
diz que as mulheres tendem, em média, a ser melhores que os homens em emoções e os homens são mais confiantes socialmente no trabalho.

Com relação aos instrumentos aplicados, infere-se, que o CNL contribuiu para a indicação complementar em Liderança. Entende-se, que há necessidade de validação do CNL e sua aplicação em larga escala. Vidergor e Sisk (2013) afirmam que as características de Liderança, empregadas nesse instrumento, pode ser usada como escala observacional para contribuir na identificação ou rastreamento dos estudantes com AHSD em Liderança.

Embasados nos estudos de Renzulli e Reis (2009) e Burns (2014), conclui-se, que o Enriquecimento surtiu positivamente aos participantes e cumpriu os objetivos propostos na pesquisa, inclusive, intervir com estudantes com AH/SD em Liderança possibilitou enxergar uma escola comprometida com as respostas educativas necessárias e asseguradas pela legislação brasileira, conforme expressa A7 "É muito bom saber que tem AHSD em liderança. Eu não me achava bom, e participando do AEE, a professora e meus colegas me falam que sou bom, que tenho boas ideias, estou acreditando e quero que os meus amigos da sala também acreditem que eles são bons em alguma coisa"

Hábitos positivos geram ambientes melhores, por sua vez, ambientes positivos constituem hábitos melhores, argumentam Covey et. al (2017). Os autores aditam que muitas escolas empregam uma postura reativa na hora de melhorar sua cultura, se deixam moldar ou seguem em altos e baixos em eventuais crises. Esses autores afirmam que, quando a cultura da escola se pauta pela alta eficácia possibilita o desenvolvimento da abordagem proativa, com uma cultura criteriosamente arquitetada, oposta àquela que vai sendo moldada ao acaso.

A partir dos resultados apresentados, coaduna-se com Renzulli (2014) ao questionar os numerosos estudos e comentários sobre Liderança discutidos na literatura da educação de estudantes com AHSD, e que ainda não se apurou a relação entre as características dos líderes acima da média e suas motivações na contribuição social que seus dons possibilitam e questiona: O que faz com que pessoas como Madre Teresa, Martin Luther King Jr. e Nelson Mandela devotem o próprio tempo e energia a empreendimentos socialmente conscientes que melhoram a vida de milhares de pessoas? Nossos programas educacionais para AHSD poderiam produzir futuros líderes coorporativos tanto sensíveis à estética e às questões ambientais quanto para as questões empresariais? Será que podemos influenciar a ética e a moralidade de futuros líderes industriais e políticos? Para responder esses questionamentos, estudos futuros são necessários, principalmente no âmbito brasileiro.

\section{Considerações Finais}

A pesquisa científica sobre AHSD em Liderança não é saliente no contexto brasileiro. As causas possíveis dessa falta podem ser que as equipes escolares visibilizem mais as áreas acadêmicas e tenham dificuldades em instrumentalizar os procedimentos de identificação das características de Liderança.

A esse respeito, os procedimentos avaliativos e de atenção às respostas educativas para as necessidades dos estudantes potenciais em Liderança são importantes de se mencionar e a urgência de capacitação das equipes gestoras e dos docentes para o trabalho com esses estudantes. Frisa-se, que o instrumento CNL, aplicado como complemento ao LIVIAHSD e QIIAHSD-PR, sugere-se o uso em larga escala para validação, se possível em outros níveis de ensino.

$\mathrm{O}$ fato de a pesquisa em tela ter sido desenvolvida por uma educadora especial da escola dos estudantes participantes facilitou a aproximação e a realização do projeto junto à equipe escolar. Os professores, gestores e familiares expressaram surpresa e satisfação com os resultados obtidos. Quanto aos participantes, eles demonstraram apreço e muito interesse por fazerem parte do PEL e deixaram claro desejarem a continuidade do projeto, cujas condições não foram favoráveis para prosseguimento para o Enriquecimento III. 
Research, Society and Development, v. 11, n. 1, e20811124756, 2022

(CC BY 4.0) | ISSN 2525-3409 | DOI: http://dx.doi.org/10.33448/rsd-v11i1.24756

Entende-se, que a produção de conhecimento científico sobre AHSD em Liderança é oportunidade imensurável, não somente para a produção de conhecimento, mas, também, contribuição para desenvolvimento de futuros líderes.

Desse modo, espera-se que os resultados da pesquisa contribuam para a descoberta e desenvolvimento de potenciais e provoquem possibilidades de estudos futuros, principalmente no tocante à sinalização de estudantes em diferentes níveis de ensino, pois, a Liderança é tema relevante para a Ciência e para uma sociedade carente de líderes positivos.

\section{Referências}

Burns, D. E. (2014). Altas Habilidades/Superdotação - Manual para guiar o aluno desde a definição de um problema até o produto final. Juruá.

Covey, S. R. et al. (2017). O Líder em Mim: como escolas ao redor do mundo estão inspirando a grandeza, uma criança por vez. Benvirá.

Cawood, J. (1998). Student Leadership in Schools: Benevolent or Malevolent. Paper presented at the European Conference on "Needed--The Gifted" cosponsored by the Landesschulrat fur Salzburg and the World Council for Gifted and Talented Children, 26-28.

Decreto $n^{\circ}$ 6.571, de 17 de setembro de 2008. (2008). Política Nacional de Educação Especial na Perspectiva da Educação Inclusiva. Brasília: MEC/SEESP.

Dionne, H. (2007). A pesquisa-ação para o Desenvolvimento Local. (16a ed.), Líber.

Farias, E. S. de, Wechsler, S. M. (2014). Desafios na identificação de alunos intelectualmente dotados. In: Virgolim, A. M., Konkiewitz, E. C. (Orgs.) Altas habilidades/superdotação, inteligência e criatividade. Papirus, 335-350.

Gardner, H. (1994). Estruturas da mente: a Teoria das Múltiplas Inteligências. Artes Médicas.

Gardner, H. (2013). Mentes Que Lideram. Como líderes eficazes criam e executam. Elsevier.

Gil, A. C. (2002). Como elaborar projetos de pesquisa. (4a ed.), Atlas.

Gil, A. C. (2008). Como elaborar projetos de pesquisa. (5a ed.), Atlas.

Golemam, D. (2011). Inteligência emocional. Objetiva.

Goleman, D. (2015). Liderança: a inteligência emocional na formação de um líder de sucesso. Objetiva.

Koga, F. O., Rossi, C. S., Rangni, R. A. (2021). Estudantes com altas habilidades ou superdotação: desdobramentos dos índices da Sinopse Estatística e do Microdados na Região Sudeste do Brasil. Research, Society and Development, 10(4), 01-15. Doi: http://dx.doi.org/10.33448/rsd-v10i4.13856

Marland, S. (1972). Education of the gifted and talented: report to the Congress of the United States by the U.S. Commissioner of Education. Government Printing Office.

Pérez, S. G. P. B., \& Freitas, S. N. (2016). Manual de identificação de Altas Habilidades/Superdotação. Apprehendere.

Pfeiffer, S., \& Wechsler, S. M. (2013). Youth leadership: A proposal for identifying and developing creativity and giftedness. Estudos de Psicologia. 2, 219229.

Reis, S., \& Renzulli, J. (2009). Creative Productivity (entry). In: B. Keer (Ed.), Encyclopedia of giftedness, creativity, and talent. 1, 194-197.

Renzulli, J., \& Reis, S. (1997) The schoolwide enrichment model: A how-toguide for educational excellence. Creative Learning Press.

Renzulli, J. (2014). A concepção no modelo dos três anéis: um modelo de desenvolvimento para a promoção da produtividade criativa. In: Virgolim, A. M., Konkiewitz, E. C. (Orgs.) Altas habilidades/superdotação, inteligência e criatividade. Papirus, p219-264.

Renzulli, J. S. (2018). Reexaminando o papel da educação para superdotados e o desenvolvimento de talentos para o século XXI: uma abordagem teórica em quatro partes. In: A. Virgolim (Org.), Altas Habilidades/Superdotação: processos criativos, afetivos e desenvolvimento de potenciais (p. 19 - 42). Curitiba, PR: Juruá.

Renzulli, J. S. (2021). Reflections on my work: the identification and development of creative of creative/productive giftedness. In D. Y. Dai \& R. J. Sternberg (Orgs.), Scientific Inquiry into human potencial: historical and contemporary perspectives acress disciplines (p.197-211). Routledge.

Sabatella, M. L. P. (2013). Talento e superdotação - problema ou solução? Intersaberes.

Sisk, D. (2000). Understanding and Encouraging Leadership Giftedness. TEXAS ASSOCIATION, For the Gifted and Talented, TEMPO, XX, 6-7.

Vidergor, H., \& Sisk, D. (2013). Enhancing the gift of leadership. Innovative programs for all grade level. The international Cengtre for Innovation in Education (ICIE). 